\title{
MOBILIZAÇÃO E RESISTÊNCIA AO PROJETO SANTA QUITÉRIA DE MINERAÇÃO DE URÂNIO E FOSFATO: O DESENVOLVIMENTO COMO AMEAÇA E A LUTA ANTINUCLEAR COMO GARANTIA DE EFETIVAÇÃO DA JUSTIÇA SOCIOAMBIENTAL
}

\author{
Francisco Hélio Monteiro Júnior ${ }^{*}$ \\ Talita Silva Bezerra*
}

\section{RESUMO}

Esse trabalho analisa a atuação dos movimentos sociais junto à Articulação Antinuclear do Ceará a fim de garantir a efetivação da justiça socioambiental diante da implementação do Projeto Santa Quitéria de Mineração no semiárido cearense. Caracterizados como "Movimentos sociais contemporâneos" tais grupos forjam um coletivo difuso, atuando nas discriminações de acesso aos bens da modernidade e, simultaneamente, criticando seus efeitos nocivos. Esta análise consiste no estudo de caso do processo de licenciamento ambiental do Projeto. Foi realizada pesquisa empírica, com observação participante nas audiências públicas realizadas no período de licenciamento ambiental nos anos de 2014 e 2015.

Palavras-chave: Desenvolvimento. Mineração. Conflito socioambiental. Movimentos Sociais. Justiça socioambiental.

\section{MOBILIZATION AND RESISTANCE TO THE SANTA QUITÉRIA PROJECT OF MINING: THE DEVELOPMENT AS A THREAT AND THE ANTINUCLEAR FIGHT AS A GUARANTEE OF THE EFFECTIVENESS OF SOCIO- ENVIRONMENTAL JUSTICE}

\begin{abstract}
This work analyzes the actions of social movements with the Antinuclear Articulation from Ceará in order to ensure the effectiveness of socio-environmental justice in implementing the Santa Quitéria Project of Mining into semi-arid region from Ceará. Characterized as 'contemporary social movements', such groups form a diffuse collective, by acting on the discriminations of access to the modernity goods and at the same time by criticizing its harmful effects. This analysis consists of the case study of the environmental licensing

\footnotetext{
* Doutor em Sociologia pelo Programa de Pós-Graduação em Sociologia da Universidade Federal do Ceará (PPGS - UFC). Mestre em Sociologia também pelo Programa de Pós-Graduação em Sociologia - PPGS da Universidade Federal do Ceará (UFC) e Bacharel em Ciências Sociais pela Universidade Estadual do Ceará (UECE).. É Professor do curso de Direito da Faculdade Luciano Feijão. Professor do curso de Direito e Gestor de Pesquisa do Centro Universitário INTA - UNINTA. Pesquisador do Grupo de Pesquisa História Social e Memória, atuando na linha de pesquisa sobre Direitos Humanos, Cultura de Paz e Políticas Públicas e do Grupo de Estudo Marias Sobralenses, atuando na linha de pesquisa sobre Violência Doméstica, ambos vinculados ao Diretório dos Grupos de Pesquisas do CNPq. Endereço postal: Rua Vereador Joaquim Barreto Lima, 797, Bairro das Nações, Sobral-CE - CEP: 62053-770. Email: heliomonteirojr@ yahoo.com.br.

* Mestra em Sociologia pela Universidade Federal do Ceará. Atualmente é professora-pesquisadora do Grupo de Pesquisas sobre Culturas Juvenis (GEPECJU - UVA/CE) vinculado ao Diretório dos Grupos de Pesquisas do CNPq. Professora no Centro Universitário INTA - UNINTA, ministrando as disciplinas de Antropologia Jurídica, Sociologia Geral e do Direito e Cidadania e Direitos Humanos. Endereço postal: Rua Vereador Joaquim Barreto Lima, 797, Bairro das Nações, Sobral-CE - CEP: 62053-770. Endereço eletrônico: talita_bezerra85@hotmail.com.
} 
process of this Project. Empirical research was carried out, with participant observation in the public hearings held during the environmental licensing.

Keywords: Development. Mining. Socio-environmental conflict. Social movements. Social and Environmental Justice.

\section{INTRODUÇÃO}

A partir do estudo de caso do processo de licenciamento ambiental do Projeto Santa Quitéria de mineração, esse trabalho pretende dar encaminhamento analítico à atuação dos movimentos sociais junto à Articulação Antinuclear do Ceará, que atuam a fim de garantir a efetivação da justiça socioambiental diante da implementação do Projeto Santa Quitéria de Mineração no semiárido cearense. Tal projeto consiste na instalação de um complexo industrial destinado a minerar e beneficiar urânio e fosfato na jazida mineral Itataia, localizada entre os municípios cearenses de Itatira e Santa Quitéria, distante 222 quilômetros da capital Fortaleza.

O Estudo de Impacto Ambiental - EIA do projeto, destaca que trata-se da maior reserva de urânio já detectada no país, estando localizada em uma área de 4.001,04 hectares. A expectativa é que anualmente 40 toneladas de material radioativo sejam transportadas entre Santa Quitéria e a capital cearense em quatro carregamentos de 25 contêineres, cada. Em Fortaleza - capital do estado, a pasta de urânio produzida na mina de Itataia - chamada yellow cake - deve ser escoada pelo Porto do Mucuripe, de onde segue para outro país.

Diante da magnitude do projeto, as empresas envolvidas e o Estado reiteram um discurso desenvolvimentista hegemônico, objetivando um "cenário perfeito" para a implementação de tal. Enquanto discurso hegemônico, o modelo de desenvolvimento agenciado pelos interessados na implementação do Projeto Santa Quitéria de Mineração acaba por ser percebido aqui como uma "imposição de grandes projetos e empreendimentos sobre territórios que violam os modos de vida local, promovendo injustiças ambientais, onde destaca-se também a atuação do Estado frente as assimetrias de poder como um promotor da vulnerabilização" (ACSELRAD, 2009). As injustiças ambientais materializam-se quando a carga dos danos ambientais do desenvolvimento se concentra, de modo predominante, em locais onde vivem populações em condições de desigualdade social, aumentando ainda mais a vulnerabilidade de tais. 


\section{MOBILIZAÇÃO E RESISTÊNCIA AO PROJETO SANTA QUITÉRIA DE MINERAÇÃO DE URÂNIO E FOSFATO: O DESENVOLVIMENTO COMO AMEAÇA E A LUTA ANTINUCLEAR COMO GARANTIA DE EFETIVAÇÃO DA JUSTIÇA SOCIOAMBIENTAL}

Podemos considerar que a atuação dos movimentos sociais na Articulação Antinuclear do Ceará contribui para o esclarecimento em relação aos riscos e ameaças de tal projeto desenvolvimentista, efetivando assim as premissas da "justiça ambiental" que, na definição de Porto (2005), é a contestação de dinâmicas discriminatórias que colocam sobre o ombro de determinados grupos populacionais os malefícios do desenvolvimento econômico e industrial. Constitui importante exemplo de resistência aos efeitos nefastos de um capitalismo globalizado, o qual utiliza sua crescente liberdade locacional de investimentos entre regiões para inibir a construção de parâmetros sociais, ambientais, sanitários e culturais direcionadores do desenvolvimento econômico e tecnológico.

A Articulação Antinuclear do Ceará vê a necessidade de se desenvolver a questão ambiental para além da busca pela preservação, mas que também almeje uma distribuição socialmente justa dos riscos ambientais produzidos pelos empreendimentos, contradizendo o pensamento ecológico neoliberal.

Para fins analíticos, distingue-se aqui dois momentos no processo de licenciamento ambiental: o primeiro se refere às audiências, encontros e seminários promovidos pelos grupos contrários à mineração do urânio e fosfato na localidade, quais sejam os movimentos sociais e entidades civis. O segundo momento abrange as audiências públicas convocadas pelo órgão responsável por emitir a licença ambiental - neste caso, o IBAMA - como etapa imprescindível do processo administrativo para emissão da licença prévia (LP). Ao invés de tratá-los como dois momentos distintos, tomamo-los como verso e reverso do processo de formação de uma "cena participativa" (Bronz, 2011; Morawska Vianna, 2014) e democrática necessária para avalizar aspectos negativos de um Projeto de Grande Escala (PGE).

Os debates realizados pelos movimentos sociais e entidades civis com a participação dos potenciais atingidos e de todos os interessados são marcados por intensa intervenção e participação daqueles, expondo suas interpretações, dúvidas, incertezas, medos e expectativas acerca do Projeto. As audiências que constam do processo administrativo, com sua estrutura formal e burocratizada, legitimada por um aparato técnico-jurídico de apresentação do PSQ pelo empreendedor, com pouco tempo disponibilizado à participação dos atingidos, não contemplam e nem encontram soluções para os conflitos e problemas reiteradamente levantados nas audiências anteriores. Sua excessiva formalidade procedimental, obsta a participação dos atingidos e a exposição de seus saberes e interpretações sobre o 
empreendimento, do ponto de vista de quem habita um território a ser transformado, acarretando uma perigosa descrença desse modus operandi, que deveria cumprir com a observância da justiça socioambiental.

$\mathrm{Na}$ pesquisa empírica, com observação participante nas audiências públicas realizadas entre os anos de 2014 e 2015, foram realizadas entrevistas com lideranças comunitárias e representantes dos movimentos sociais. A análise de tais entrevistas e dos debates travados nas audiências públicas demostram claramente que o licenciamento ambiental para a implementação da jazida mineral de Itataia impulsiona um conflito socioambiental movido por interesses antagônicos.

Apresentamos os movimentos sociais como "ações sociais coletivas de caráter sóciopolítico e cultural que viabilizam distintas formas da população se organizar e expressar suas demandas" (Gohn, 2003, p. 18). No contexto da pesquisa, destaca-se a atuação da Comissão Pastoral da Terra (CPT), Cáritas Diocesana de Sobral e o Movimento dos Trabalhadores Rurais Sem Terra (MST), as Associações dos Moradores dos municípios que organizam suas ações junto à Articulação Antinuclear do Ceará. Tais grupos são pensados a partir da ideia de Movimentos Sociais Contemporâneos, que de acordo com Gohn (2003, p. 122-123), “constituem um coletivo difuso, não hierarquizado, em luta contra as discriminações de acesso aos bens da modernidade, e, ao mesmo tempo, crítico de seus efeitos nocivos, a partir da fundamentação de suas ações em valores tradicionais, solidários, comunitários".

\section{UM "DRAGÃO ADORMECIDO" NO SEMIÁRIDO CEARENSE: O PROJETO SANTA QUITÉRIA DE MINERAÇÃO E A CONSORCIAÇÃO COMO ESTRATÉGIA}

O Projeto Santa Quitéria está sob a responsabilidade do Consórcio Santa Quitéria (CSQ), que é uma parceria público privada (PPP) entre a empresa Indústrias Nucleares do Brasil S/A (INB) e a empresa Galvani Indústria, Comércio e Serviços S. A. e consiste na instalação e operação da mina de urânio e fosfato de Itataia, localizada entre os municípios cearenses de Itatira e Santa Quitéria e referenciada pelos moradores locais como o "dragão adormecido".

A INB é uma empresa de economia mista, vinculada ao Ministério da Ciência e Tecnologia, que possui monopólio do urânio no Brasil (Artigo 177 da Constituição Federal/1988) e atua em toda sua cadeia produtiva, que vai da mineração à fabricação do 


\section{MOBILIZAÇÃO E RESISTÊNCIA AO PROJETO SANTA QUITÉRIA DE MINERAÇÃO DE URÂNIO E FOSFATO: O DESENVOLVIMENTO COMO AMEAÇA E A LUTA ANTINUCLEAR COMO GARANTIA DE EFETIVAÇÃO DA JUSTIÇA SOCIOAMBIENTAL}

combustível que gera energia elétrica nas usinas nucleares. Criada em 1988, no período correspondente à redemocratização do país, a INB substituiu a Empresas Nucleares Brasileira S/A (Nuclebrás). Para a implementação do Projeto Santa Quitéria, o governo estadual também tem participação através da Agência de Desenvolvimento do Estado do Ceará (ADECE), que investirá em obras de infraestrutura como pavimentação das estradas que dão acesso ao local da mina, adutora de água e fornecimento de energia.

Data de 1976 o primeiro processo de licenciamento no Departamento Nacional de Produção Mineral (DNPM) para exploração minerária na Fazenda Itataia, quando a senhora Prudenciana Sabóia requereu uma área de 170 hectares para a exploração de calcário. No mesmo ano, a antiga Empresas Nucleares Brasileiras S/A (Nuclebrás) requereu 20.000 hectares para exploração e pesquisa de urânio, após a compra da fazenda, motivada pelos indícios da reserva de urânio no local.

O conhecimento e o interesse por parte dos representantes dos governos federal e estadual das reservas de urânio no estado do Ceará não são recentes. As reservas uraníferas foram descobertas durante a gestão do governador Cesar Cals, que empreendeu esforços quando ministro das Minas e Energia, entre os anos de 1979 e 1985, para se levar adiante a instalação da mina, perdendo o empreendimento para Poços de Caldas. Cesar Cals, durante sua gestão como governador do Estado do Ceará, entre os anos de 1971 e 1975, já havia executado um plano de governo agressivo no campo da mineração, mostrando seu interesse na expansão e regulação dessa atividade econômico-social, implantando:

[...] um sistema de financiamento à pesquisa e lavra minerais, quer a pessoas físicas detentoras de alvarás, quer a empresas de mineração; instituição de um programa de fomento à pesquisa, objetivando atrair o investidor e minorar o risco de investimento em prospecção, incluindo o oferecimento de recursos técnicos carentes e aplicação de recursos em obras de infraestrutura, tais como energia elétrica e estradas; formação e aperfeiçoamento de pessoal qualificado. (CALS, 1974, p. 31, grifo do autor)

De lá para cá, outras solicitações de exploração e pesquisa mineral foram feitas, incluindo o elemento fosfato, até chegar à emissão de Licença Prévia e Licença de Instalação, no ano de 2004, pela Superintendência Estadual do Meio Ambiente do Ceará (SEMACE) que deu mais visibilidade política ao empreendimento ao gerar um impasse jurídico em torno da competência deste órgão em licenciar uma atividade que não teria apenas a extração de 
fosfato mas também de urânio, ou seja, material nuclear monopólio da União, portanto, de competência do IBAMA. ${ }^{1}$

No caso em tela, o EIA/RIMA fora aceito pelo Ibama em fevereiro de 2015. É o documento principal com o qual a prefeitura de Santa Quitéria, a AACE e a população contam nesse momento para balizar as ações do Consórcio Santa Quitéria. O EIA/RIMA figura, prontamente, um documento de esclarecimento de como funcionará a mina - mesmo que a linguagem técnica utilizada contribua mais para obstar do que favorecer a formação de um cenário de discussão pública - e apresenta as propostas de compensação aos impactos gerados pelo empreendimento. Ele é apresentado pelo empreendedor em uma audiência pública exigida para a emissão da Licença Prévia (LP), que compõe um dos requisitos administrativos do processo de licenciamento ambiental, o qual conta ainda com Licença de Instalação (LI) e Licença de Operação (LO).

Atualmente, aguardam-se as respostas do Consórcio ao parecer técnico do IBAMA analisando o Estudo de Impacto Ambiental (EIA) do Projeto Santa Quitéria. Nele, encontra-se dentre tantos questionamentos, aquele que interroga a viabilidade hídrica do empreendimento, considerando a escassez de água da região na qual ele está localizado, solicitando do Consórcio Santa Quitéria a comprovação da viabilidade ambiental do Projeto.

Um projeto econômico de grande escala (PGE), como discutido por Baines (2014), Santos (2013) e Ribeiro (1985; 2008a; 2008b) acarreta diversos impactos socioambientais para os grupos diretamente afetados pelas grandes obras econômicas. Os PGE’s geralmente são projetos de infraestrutura que estão na base da construção de cidades planejadas, da construção de hidrelétricas, de complexos siderúrgicos e portuários, de canais hídricos e

${ }^{1} \mathrm{O}$ artigo $3^{\text {o }}$ da Resolução 001-1986 do CONAMA afirmava "Dependerá de elaboração de estudo de impacto ambiental e respectivo RIMA, a serem submetidos à aprovação da SEMA, o licenciamento de atividades que, por lei, seja de competência federal". A Resolução 237/1997 do CONAMA revoga esse artigo e resolve em Art. $3^{\circ}$ "A licença ambiental para empreendimentos e atividades consideradas efetiva ou potencialmente causadoras de significativa degradação do meio dependerá de prévio estudo de impacto ambiental e respectivo relatório de impacto sobre o meio ambiente (EIA/RIMA), ao qual dar-se-á publicidade, garantida a realização de audiências públicas, quando couber, de acordo com a regulamentação". Parágrafo único. "O órgão ambiental competente, verificando que a atividade ou empreendimento não é potencialmente causador de significativa degradação do meio ambiente, definirá os estudos ambientais pertinentes ao respectivo processo de licenciamento". Compete ainda ao IBAMA, de acordo com artigo $4^{\circ}$, inciso IV, ainda da Resolução 237/1997 do CONAMA, o licenciamento ambiental de "[...] empreendimentos e atividades com significativo impacto ambiental de âmbito nacional ou regional", como atividades "[...] destinadas a pesquisar, lavrar, produzir, beneficiar, transportar, armazenar e dispor material radioativo, em qualquer estágio, ou que utilizem energia nuclear em qualquer de suas formas e aplicações, mediante parecer da Comissão Nacional de Energia Nuclear - CNEN". Para mais detalhes sobre os impasses do processo de licenciamento ambiental, ver EIA/RIMA, Projeto Santa Quitéria, volume I, p. 123-133, e Medeiros e Diniz (2015). 


\section{MOBILIZAÇÃO E RESISTÊNCIA AO PROJETO SANTA QUITÉRIA DE MINERAÇÃO DE URÂNIO E FOSFATO: O DESENVOLVIMENTO COMO AMEAÇA E A LUTA ANTINUCLEAR COMO GARANTIA DE EFETIVAÇÃO DA JUSTIÇA SOCIOAMBIENTAL}

grandes linhas ferroviárias que albergam a ideia nada ingênua de serem promotores da "modernidade" e do "progresso"2 mediante a promoção do desenvolvimento econômico e social.

Essa "modernização" chega acirrando ou fomentando conflitos socioambientais em que agricultores, ribeirinhos e povos indígenas tem seu cotidiano e suas relações sociais modificadas pelas intervenções de consórcios que conjugam os interesses estatais e privados. Pode-se citar a construção de barragens que obrigam a remoção de agricultores, criadores e ribeirinhos de seu lugar de pertencimento para outras localidades e as variadas atividades de mineração que além de propiciarem a possível contaminação do solo e do ar com o radônio gás radioativo inodoro, incolor e insípido, requerem grandes quantidades de água em suas etapas de produção, comprometendo o acesso daqueles segmentos a esse bem tão caro à vida.

O Projeto Santa Quitéria compreende diversas obras e instalações em sua fase de construção e operação, destacando a construção de um canteiro de obras e infraestrutura de apoio durante sua fase de implantação, estradas de acesso, a própria mina, barragem de rejeitos, instalação mínero industrial, instalação nuclear, instalações administrativas, sistema de carga, descarga, transporte, transferência e estocagem, entre outras obras e instalações além de infraestrutura (fornecimento de água, energia, estradas e capacitação de mão de obra).

Para além de toda a estrutura já mencionada, a consorciação formada entre o governo federal e a empresa privada Galvani Indústria, Comércio e Serviços S. A. viabilizou técnica e economicamente o PSQ na medida em que garantiu aquisição de tecnologia para a prospecção do urânio e investimento financeiro advindo do interesse do capital transnacional na produção do fosfato. Como o PSQ envolve a mineração de um minério nuclear que é monopólio da União, o empreendimento é regido pelas normas de direito público e pelas leis específicas do setor. Isso quer dizer que o PSQ tira "vantagens" da consorciação, se beneficiando de prerrogativas legais e do poder que tem a INB como empresa pública. Vejamos como isso se coloca no EIA - Santa Quitéria (2014, p. 33):

\footnotetext{
${ }^{2}$ A ideia de progresso aqui é tratada como elemento presente na ideologia da redenção como definida por Ribeiro (1985) e que marca os projetos de grande escala, ao assumirem o compromisso de gerar numerosas oportunidades de emprego direto e indiretos, com a construção de grandes obras, tirando uma região ou um país do atraso econômico. Nas palavras do autor: "a idelogía de la redención cuya matriz principal es la ideología del progresso, que muchas vezes toma la forma del desarrollismo, es decir, la suposición de que los proyectos de gran escala son positivos porque desarrollarán uma región, suministrando bienestar a todo el mundo." (Ribeiro, 1985, p. 33).
} 
[...] embora de iniciativa mista, público-privada, o empreendimento está lastreado no interesse coletivo e na utilidade pública, razão pela qual poderão ser invocadas pelo Consórcio Santa Quitéria, e autorizadas pelo órgão ambiental competente, se necessário for, todas as hipóteses legais de exceção às restrições ambientais de uso dos recursos naturais e ocupação da área pretendida, para que o empreendimento possa ser instalado e vir a operar, sem prejuízo da sua obrigação em adotar medidas de mitigação e compensação dos impactos ambientais que vier a dar causa. Vale lembrar que o empreendedor, no caso, o Consórcio, poderá utilizar até mesmo o poder expropriatório que a INB, enquanto órgão do governo federal possui, 27 para adquirir o domínio ou instituir servidão das áreas particulares porventura necessárias à consecução de seu projeto, para além da poligonal minerária.

Essa passagem do EIA esclarece com detalhes os efeitos ameaçadores do PSQ que se encontram velados, que não são ditos nos eventos públicos e nem nas audiências públicas, decorrentes do poder adquirido pelo CSQ por meio do processo de Consorciação. Ao Consórcio será permitido, com obediência às normas ambientais competentes, invocar as “[...] hipóteses legais de exceção às restrições ambientais de uso dos recursos naturais e ocupação da área pretendida", inclusive utilizar-se de poder expropriatório que a INB possui "[...] para adquirir domínio ou instituir servidão" das áreas que não são objeto do licenciamento. Essa permissão, presente em outros estudos de impacto ambiental, permite ao empreendedor ampliar sua área de atuação.

Assim o PSQ age silenciosamente impactando a vida das comunidades. Essa margem de incertezas na qual se realiza a investidura de poder agir em conformidade a uma "hipótese legal de exceção às restrições ambientais" se soma aos sentimentos de desconfiança sobre os objetivos do Projeto entre os membros das comunidades. Sobretudo daquelas que vivem bem próximo à fazenda Itataia. A forma legalizada de atuar do Consórcio é legitimada pelos discursos de convencimento que descrevem o PSQ como um projeto sustentável e de interesse nacional, disfarçando assim os interesses privados.

\section{as AUdiênCias públicas COMO ESPaÇOS DE LUTA EM MEIO A AFIRMAÇÃO E CONTESTAÇÃO DA VIABILIDADE DO PSQ}

É com atenção voltada para o monitoramento da qualidade dos bens hídricos e da reprodução de seu modo de vida que as comunidades resolveram lutar contra o PSQ. Essa luta se dá mediante a sua participação e a dos movimentos sociais alinhados à Articulação Antinuclear do Ceará nos espaços de decisão (audiências públicas) e utilizando de meios 


\section{MOBILIZAÇÃO E RESISTÊNCIA AO PROJETO SANTA QUITÉRIA DE MINERAÇÃO DE URÂNIO E FOSFATO: O DESENVOLVIMENTO COMO AMEAÇA E A LUTA ANTINUCLEAR COMO GARANTIA DE EFETIVAÇÃO DA JUSTIÇA SOCIOAMBIENTAL}

legais e formais (relatórios, análises jurídicas e técnicas), afirmando que os seus bens hídricos, suas terras e suas criações lhes pertencem e serão afetadas diretamente pelo PSQ.

Há, no sentido weberiano, uma "luta pacífica" (WEBER, 2012, p. 23) em que os indivíduos concorrem, sem o uso da violência física, para obter para si o poder de “[...] disposição sobre oportunidades desejadas também por outras pessoas", uma concorrência pela "verdade" e pelo que os recursos naturais, sobretudo a água, representam para os moradores e o empreendimento.

Por sua vez, para negar estrategicamente essa luta que representa uma discordância em relação ao Projeto, o Consórcio nega essa concorrência, afirmando que os recursos hídricos disponíveis serão suficientes apara atender a mina. A luta que marca uma forma de relação social, como conceituada por Weber (2012), em que os grupos e indivíduos tentam impor sua própria vontade e interpretação contra a resistência de outros grupos, marca a relação entre opositores e defensores do PSQ. Os primeiros construindo e disseminando uma percepção da ameaça de contaminação que representa a mina para seus bens hídricos; o segundo impondo uma leitura da segurança do empreendimento e dos seus benefícios para a região, que chega para empolgar: “[...] quando a INB vem pra mostrar o lado bom da moeda, as pessoas se empolgam muito", afirma seu Júnior Paiva.

A luta fornece também um sentimento de unidade à comunidade e de urgência para defender sua existência (SIMMEL, 1983). Diria que o próprio sentimento de pertencimento a uma comunidade se constitui, dentre outros fatores, como um efeito dos sentimentos contraditórios suscitados por um projeto de grande escala, encarado como um inimigo externo a ser combatido. A luta, aliada a uma experiência de "existência coletiva" da comunidade mais a revalorização de sua cultura camponesa, fornece um espírito de união para atuar contra o elemento estrangeiro, que, nesse caso, é o PSQ e sua proposta de desenvolvimento que ameaça a qualidade de seus bens hídricos e as formas de sociabilidade que são fundamentais para a reprodução do campesinato.

As audiências públicas são um momento importante do processo de discussão acerca dos grandes projetos econômicos e consistem em espaços de luta. No caso do PSQ, desde 2010 são realizadas audiências públicas em que defensores e opositores ao projeto expõem seus pontos de vista sobre o Projeto Santa Quitéria. 
Tivemos acesso a dados e depoimentos de quatro audiências que ocorreram entre os anos de 2010 e 2015 e participamos das audiências públicas ocorridas no dia 07 de abril de 2014 e mais duas dias 16 e 17 de novembro de 2015. Estes eventos demarcam uma "suspensão" importante no tempo transcorrido de todo o processo que envolve a execução de uma grande obra econômica, a saber, a cada audiência os grupos que conflituam os seus interesses se encontram para hipoteticamente negociarem e acordarem suas reivindicações.

Elas garantem aos grandes empreendimentos uma legitimidade formal sem a qual os "benefícios" de uma grande obra realizada em nome de avanços socioeconômicos para uma dada região, neste caso o semiárido cearense, não ganharia estatuto de verdade. Como assevera Zhouri, Laschefski e Paiva (2014, p.107), o procedimento de ouvir a comunidade cumpre com uma determinação formal, “[...] importante para legitimação da cena democrática em que se dá a definição do que seja "bem público".

A audiência pública ocorrida no dia 07 de abril de 2014, foi promovida pela Câmara Municipal de Santa Quitéria, em parceria com a Assembleia Legislativa do Estado do Ceará. Esta não se insere na agenda de encontros obrigatórios do processo administrativo de licenciamento, mas foi importante na construção de uma "cena participativa" que engloba encontros e atividades promovidas pela empresa a fim de "domesticar os conflitos sociais". (MORAWSCA VIANNA, 2014). Compõe essa cena a iniciativa dos movimentos sociais que também articulam encontros e reuniões com o intuito de colocar em outros termos os pontos discordantes e aqueles que acabam sem negociação.

Outro momento que contribuiu para a formação da "cena participativa" ocorreu em 2010. Refiro-me à audiência promovida pela Cáritas Diocesana, com a presença do Núcleo TRAMAS/UFC, Movimento dos Sem Terras - MST -, da Comissão Pastoral da Terra - CPT e do Movimento Sindical dos Trabalhadores/as Rurais. A audiência aconteceu na comunidade Riacho das Pedras, com participação de outras comunidades do entorno da Mina. Estiveram presentes representantes da prefeitura de Santa Quitéria, da Galvani S\&A (empresa privada) e das Indústrias Nucleares do Brasil - INB, que fizeram parte da mesa juntamente com todas as outras instituições citadas.

Para Erivan, membro da Articulação Antinuclear do Ceará, o resultado daquela audiência foi '“[...] negativo, pois não se chegou a qualquer consenso (grifo do autor) sobre os malefícios da extração de urânio e fosfato e muito menos dos pontos positivos apresentados pelo governo e as empresas". Diante do insucesso da audiência em promover um consenso 


\section{MOBILIZAÇÃO E RESISTÊNCIA AO PROJETO SANTA QUITÉRIA DE MINERAÇÃO DE URÂNIO E FOSFATO: O DESENVOLVIMENTO COMO AMEAÇA E A LUTA ANTINUCLEAR COMO GARANTIA DE EFETIVAÇÃO DA JUSTIÇA SOCIOAMBIENTAL}

sobre os "malefícios da mina", sob posicionamentos conflitantes que o debate sobre o Projeto Santa Quitéria inexoravelmente provoca, a Articulação Antinuclear soma seus esforços no trabalho junto às comunidades impactadas do entorno da mina.

Para além dos trabalhos comunitários, essas audiências públicas, convocadas sobretudo pelas instituições públicas e/ou privadas que têm interesses políticos, e, portanto, politizam o debate sobre a viabilidade da execução do Projeto Santa Quitéria, chamamos de audiências públicas normativas. São momentos públicos utilizados pelos empreendedores para, como afirma Bronz (2011, p. 42), exibirem seus discursos empresariais "[...] de um empreendimento imaginado com todas as soluções tecnológicas e medidas de controle possíveis de serem idealizadas", objetivando a construção de um cenário perfeito para a aprovação do Projeto pela opinião pública. Nesse caso, elas diferem das audiências organizadas pelos impactados de um grande projeto de desenvolvimento em parceria com movimentos sociais, que invertem a lógica da participação cedendo mais tempo para a fala dos opositores, como estudantes, pesquisadores, membros dos movimentos sociais, das comunidades impactadas, dentre outros que nas audiências públicas normativas jamais compunham a mesa de representação das entidades envolvidas com o empreendimento.

A audiência do dia 07 de abril de 2014 foi pensada como uma forma de antecipar debates e discussões que normalmente ocorrem nas audiências públicas promovidas pelos órgãos públicos competentes como etapa formal do processo administrativo do licenciamento ambiental, um dos raros momentos em que é prevista a participação de todas as partes interessadas em debater o projeto de grande escala, sua viabilidade, seus impactos e as possíveis ações mitigadoras desses impactos.

Contudo, essa participação se resumiu, como em outros momentos, em expor opiniões favoráveis e contrárias. Não houve um tempo para o diálogo ou para o debate mais detalhado sobre questões de difícil entendimento. Os defensores do Projeto que compunham a mesa, utilizaram de seu largo tempo de fala para retrucar e desqualificar a fala dos oposicionistas, que contaram com um tempo que vem se mostrando insuficiente e concedido de forma exígua para as suas exposições. Isso reflete diretamente na quantidade de pessoas contrárias ao PSQ que têm oportunidade de falar.

Seria uma oportunidade singular de estarem juntas lideranças governamentais, consórcio, movimentos sociais e população debatendo o PSQ, sem as amarras institucionais e 
burocráticas do Licenciamento Ambiental. O então ex-deputado estadual Tomás Figueiredo Filho (2007-2011), um dos membros da mesa, defensor e articulador político do Projeto, assim se expressou sobre a audiência: “[...] nós estamos antecipando uma audiência pública que é exigida pelo IBAMA, para avaliar o desejo da população [...]". Porém, a "avaliação dos desejos da população" se converteria em uma estratégia de "domesticação" desses desejos a partir da apresentação das vantagens econômicas da mineração do urânio e do fosfato, comumente usadas pelos seus apoiadores nas audiências públicas, em um clima em que o acirramento das posições marcou toda aquela manhã. Se aprendemos nas aulas de matemática básica que a ordem dos fatores não altera o produto, nas audiências essa regra não se sustenta. Os que falaram primeiro, e esse raciocínio também é valido para as audiências do processo de licenciamento ambiental, foram os legítimos representantes da fala autorizada, investidos da autoridade que o cargo público, a formação científica ou a representatividade lhes conferem.

Aqueles que tiveram oportunidade de marcar um posicionamento contrário foram hostilizados ou mesmo tiveram sua fala desacreditada como estratégia de nulificar os dados, como foi o caso da professora Raquel Rigotto, membro da AACE. Ela falou que os grandes empreendimentos trazem três grupos de problemas que já poderiam estar sendo antecipados, prevenidos e evitados. O primeiro é o comprometimento do acesso aos bens naturais pela população; o segundo diz respeito aos deslocamentos que deverão ser realizados pelas pessoas que moram nas proximidades da mina, e, por último, o próprio processo de produção do fosfato e urânio, que pode acarretar desastres, acidentes de trabalho, intoxicações agudas e diversas doenças crônicas.

Gledson Mendes, membro e naquela audiência, representante do MST, dissertou sobre a relação da mineração do fosfato com o agronegócio, mas teve como reposta, por parte da mesa, que o que mal faz são os agrotóxicos e não o fosfato. Como se ambos não tivessem relação com um modelo de agricultura em larga escala que necessita de fertilizantes e agrotóxicos para manter os níveis de produtividade requeridos pelo capital.

Seu José Pinto de Albuquerque, então vice-presidente da região norte da Federação da Agricultura e Pecuária do Estado do Ceará (FAEC), e o deputado Carlomano Marques (PMDB), ambos defensores do PSQ, recorreram ao argumento que defende o desenvolvimento da nação vinculado à obrigação de " [...] pensar novas fontes de energia para o Brasil, como energia eólica, energia da biomassa, energia do álcool, energia dos rios, e por que não a energia da usina nuclear? Colocaram em uma escala horizontal, fontes de energia 


\section{MOBILIZAÇÃO E RESISTÊNCIA AO PROJETO SANTA QUITÉRIA DE MINERAÇÃO DE URÂNIO E FOSFATO: O DESENVOLVIMENTO COMO AMEAÇA E A LUTA ANTINUCLEAR COMO GARANTIA DE EFETIVAÇÃO DA JUSTIÇA SOCIOAMBIENTAL}

que não são tratáveis da mesma forma e que apresentam especificidades quanto à sua empregabilidade, viabilidade econômica e seus impactos.

Nas audiências públicas do processo de licenciamento do PSQ, os representantes da INB e do Conselho Nacional de Energia Nuclear se investem constantemente de uma autoridade, recorrendo a essas fontes e lembrando aos ouvintes de sua formação científica e de seus títulos de doutoramento na área de física nuclear para distanciar-se socialmente dos membros das comunidades e lideranças populares, que são destituídos dos códigos dominantes, logo descredenciados, segundo o posicionamento dos técnicos e de parlamentares favoráveis ao Projeto para afirmar alguma "verdade".

Os pontos mais discordantes acerca do Projeto Santa Quitéria se referem aos riscos que a mineração de urânio possui à saúde humana e a sua viabilidade hídrica. Os confrontos de opinião tecidos nos espaços públicos e acadêmicos acerca dessas questões recaem em uma corda de forças que vence aquele que dispuser de meios políticos e econômicos para impor seu ponto de vista. Dessa forma, paira uma incerteza que chega aos moradores impactados e envolve gestores públicos responsáveis por balizar as vantagens/desvantagens do PSQ.

Sobretudo quando o que se discute é a poluição por material radiativo, a compreensão de como os termos científicos e técnicos são acionados pelos apologistas é condição para uma postura política e de emancipação por parte dos impactados e opositores ao PSQ. Por isso, a AACE opta por realizar um trabalho que compreenda a participação dos membros das comunidades impactadas nos debates sobre a mina de Itataia, onde os discursos ideológicos da redenção e da sustentabilidade são desconstruídos, para que estes ajam como replicadores de uma leitura que foca na representação da ameaça do empreendimento, que é o avesso da imagem otimista repassada pelo Consórcio Santa Quitéria e outros apologistas do Projeto.

Para barrar esse otimismo em relação ao PSQ, vem se dando destaque para a questão hídrica que envolve o processo de mineração. Durante essa audiência e em tantas outras observamos que não há um reconhecimento por parte dos empreendedores de que o PSQ representa uma ameaça para a quantidade e qualidade dos recursos hídricos da região. Apesar de os técnicos da Companhia de Gestão dos Recursos Hídricos do Estado do Ceará COGERH - afirmarem que o Estado está atento para cuidar da qualidade desses recursos, sobretudo do Açude Edson Queiróz, “[...] para não prejudicar todas as cadeias econômicas 
que necessitam dele", não esclarecem como isso será feito diante de um cenário de escassez de chuva e da quantidade de água que requer o empreendimento.

Esse questionamento, apresentado pelos movimentos sociais como MST e AACE, é respondido com dados estatísticos pelos técnicos da COGERH, que intentam mostrar por meio de uma linguagem objetiva, que há açudes com capacidade para armazenar água "suficiente" para atender ao empreendimento e à população. Contudo, quando confrontada pela seca, pelos argumentos que redirecionam o debate para uma nova agenda de desenvolvimento que priorize as comunidades que não se consegue convencer pelo uso da linguagem ordinária, acessível aos impactados pelo PSQ.

Essa postura, por vezes intolerante, daqueles que conduzem o processo responsável pela efetivação dos PGEs, dá o tom às audiências públicas em que ocorre a apresentação formal do EIA/RIMA. A formalidade é caracterizada pela solenidade que marca essas audiências, que se revelam como rito de passagem para a homologação de acordos políticos e econômicos já tecidos anteriormente, tornando os grandes projetos econômicos viáveis. $\mathrm{O}$ espaço e o tempo concedidos ao posicionamento daqueles grupos que se colocam politicamente contrários por razões diversas e distintas é um momento importante para expor suas razões, mas acabam violentamente esvaziados de sua significância por parte dos grupos que defendem um PGE.

Contudo, isso não é suficiente para sufocar as insurgências que pipocam nas comunidades a cada momento que um morador muda de opinião sobre o PSQ ou fortalece sua posição contrária ao empreendimento. A dúvida é, neste caso particular, um bom sentimento para gerar resistências e conformar um amplo espaço para o debate. Mesmo por que a questão nuclear não pode ser tratada com certezas absolutas.

\section{O PROJETO SANTA QUITÉRIA E A DEMOCRATIZAÇÃO DOS RISCOS E PERIGOS PELA LEITURA DA ARTICULAÇÃO ANTINUCLEAR DO CEARÁ}

A ideia de risco está estreitamente relacionada à Era Nuclear, principalmente à detonação das bombas nucleares em Hiroshima e Nagasaki durante a $2^{\text {a }}$ Guerra Mundial. Contudo, ela nos remete ao processo de modernização identificado com a industrialização em massa, o tecnicismo e a mercantilização da economia e das relações sociais, ou, como conceitua Beck (2010, p. 23), “[...] o salto tecnológico de racionalização e transformação do 


\section{MOBILIZAÇÃO E RESISTÊNCIA AO PROJETO SANTA QUITÉRIA DE MINERAÇÃO DE URÂNIO E FOSFATO: O DESENVOLVIMENTO COMO AMEAÇA E A LUTA ANTINUCLEAR COMO GARANTIA DE EFETIVAÇÃO DA JUSTIÇA SOCIOAMBIENTAL}

trabalho e da organização". Nesse sentido, os riscos a que se refere Beck são globais e distinguem-se dos riscos individuais vivenciados pelo aventureiro que assume o risco de fracassar em seu empreendimento, pois colocam sob ameaça indivíduos, comunidades e populações inteiras. (BRUSEK, 2001).

A contaminação radioativa, a poluição do ar, dos rios e do solo e os riscos à saúde humana, efeitos das atividades nucleares, são a expressão de um discurso catastrófico que gera as ameaças de explosão de artefatos nucleares, a construção de submarinos atômicos, usinas energéticas e fábricas que manuseiam materiais nucleares para abastecer a cadeia produtiva da geração de energia nuclear. Todas essas ameaças são riscos globais que unificam todos na sociedade de risco diante dos danos invisíveis que trouxe o modo de vida da sociedade moderna.

Seguindo Brusek (2001) o risco é um acontecimento futuro, algo que poderá ocorrer ameaçando pessoas, bens, conquistas e objetos. Enquanto ele não acontece, prevalece um sentimento de expectativa de que algo venha a acontecer. É a primeira situação do risco. No segundo momento, o risco que passa a ser percebido torna-se um perigo. É o caso do PSQ para aqueles e aquelas que o veem como ameaça.

O perigo possui um tom ameaçador porque com a iminente concessão da licença ambiental e a percepção do que é o PSQ, as perdas que passarão as comunidades no entorno da mina deixaram de ser presumíveis e tornaram-se uma realidade concreta. Há a certeza de que elas serão provenientes dos danos que a licença ambiental acarretará. Essas ameaças são visíveis e perceptíveis para os impactados pelo PSQ. São também, por estas razões, que o desenvolvimento ameaçador se refere ao "[...] reconhecimento da imprevisibilidade dos [danos] das ameaças" (BECK, 2012) e aos danos (aspectos negativos, excetuando-se os efeitos positivos - a constituição e o fortalecimento da própria noção de comunidade, de identidade, dos valores socioculturais compartilhados) de um grande projeto de desenvolvimento como percebido pelas lideranças comunitárias e pelos movimentos sociais.

Os sujeitos que correm mais risco, em uma divisão social de "distribuição dos malefícios", utilizando uma expressão de Beck (2012), continuam sendo a população subalterna dos países em desenvolvimento. Os riscos também são uma questão de classe, que contribui na sua formatação. A sua construção e percepção dependem das relações sociais conflitivas que estão na sua órbita dando-lhe cheiro, cor e sabor. 
Na construção da percepção dos riscos do PSQ, destacamos a atuação da AACE, que conta com uma diversidade de atores sociais, das mais diferentes áreas do saber, convocando audiências e seminários junto às comunidades impactadas e divulgando material educativo e elucidativo. A cartilha intitulada No Ceará: a peleja da vida contra o urânio, produzida pela Cáritas Diocesana de Sobral (CDS) em colaboração com a AACE, destaca o que nela é chamado de cultura camponesa, com seu modo de fazer e ver o mundo.

Dividida em nove capítulos, traz uma leitura catastrófica e aponta para ameaças e impactos diretos que estão presentes na primeira etapa do ciclo do combustível nuclear. Ela está dividida nos seguintes capítulos: 1 . O chão da beleza merece ser respeitado; 2 . Territórios ameaçados; 3. Urânio, fosfato e energia nuclear - o que é?; 4. Energia cara e perigosa: como o nuclear é explorado no Brasil; 5. As ameaças do presente que temos em Caetité; 6. Caminhos de luta da Articulação Antinuclear do Ceará; 7. Resistências camponesas; 8. Nas tramas da pesquisa-ação; 9. Alternativa camponesa à Mina de Itataia

Dentre os contra-argumentos, destacamos os seguintes que convergem para as ameaças da mineração ao homem e ao ambiente: “A exploração de fosfato e urânio em larga escala ameaça a vida e a saúde" a mineração do urânio está relacionada ao "aumento do número de casos de câncer"; "minas de urânio inevitavelmente poluem o ambiente" pela “contaminação, por urânio, do lençol freático" por meio de "vazamentos ou transbordamentos nas instalações durante o processo de extração e transformação em concentrado de urânio e nas usinas nucleares" e nas "barragens de rejeitos [que] causam poluição através de vazamento" (CÁRITAS DIOCESANA DE SOBRAL - CDS). Esses argumentos são construídos destacando-se os danos e a imprevisibilidade de outros malefícios que o empreendimento é portador potencial:

\footnotetext{
A mineração de urânio é considerada como de alto risco à saúde devido às possibilidades de contaminação do solo e das águas por resíduos que, por sua vez, podem ser responsáveis por doenças que afetam as regiões ósseas e renais, causam diferentes tipos de câncer e têm chance de se constituir como fator mutagênico e com possíveis consequências hereditárias. Todas essas enfermidades podem vir a afetar seres humanos e animais que vivem na região. (CARITAS DIOCESANA DE SOBRAL - CDS, p. 11-12).
}

A polarização dos argumentos recai na oposição entre o que é falso e verdadeiro, do risco legítimo ou devaneio de quem quer instituir um clima de medo. Essas disputas, ainda que tragam consigo uma miríade de dados quantitativos ou indicadores que afirmam ou relativizam o risco, fica a princípio claro que em ambos os casos os riscos são construções. 


\section{MOBILIZAÇÃO E RESISTÊNCIA AO PROJETO SANTA QUITÉRIA DE MINERAÇÃO DE URÂNIO E FOSFATO: O DESENVOLVIMENTO COMO AMEAÇA E A LUTA ANTINUCLEAR COMO GARANTIA DE EFETIVAÇÃO DA JUSTIÇA SOCIOAMBIENTAL}

Por exemplo, em Guimarães e Mattos (2011, p. 64-70), encontramos um quadro de assertivas antinucleares em que são apontados os riscos que também apresentaria a mineração do urânio, se não tivéssemos disponíveis todo o aporte tecnológico e as técnicas de engenharia para assegurar sua minimização. Os riscos apontados são em alguma medida muito semelhantes àqueles levantados pelos opositores ao PSQ para barrar a efetivação da mina. A diferença é que os riscos são minimizados pela leitura da segurança, que vemos - no mesmo quadro de assertivas antinucleares - uma segunda coluna intitulada "principais pontos de resposta" às "assertivas antinucleares comuns" que procuram respondê-las tecnicamente e cientificamente. Vê-se aí que os riscos de contaminação e poluição pela mineração são minimizados, como podemos constatar nas seguintes afirmações: “[...] a mineração de urânio é altamente regulamentada na maior parte dos países, e as normas garantem que não há riscos de efeitos adversos"; "hoje as minas de urânio têm como objetivo atingir emissão zero de poluentes. Qualquer água liberada é de escoamento superficial e se aproxima do padrão potável [...]”. (GUIMARÃES; MATTOS, 2011, p. 64).

Uma rápida análise comparativa com a literatura técnica sobre energia nuclear põe em contraste o que chamamos de uma leitura catastrófica daqueles que rechaçam a energia nuclear e, por sua vez, a mineração do urânio, e a leitura da segurança, que minimiza os riscos e constrói um cenário ideal de funcionamento e operação de um complexo mínero-industrial que não coincide com a realidade apresentada em Caetité e antecipadamente em Santa Quitéria, para ficarmos nesses dois casos.

\section{CONCLUSÃO}

A ideia da promoção de um desenvolvimento local por um grande empreendimento suscita uma série de interpretações. Por se tratar de um projeto de mineração basilar para o prosseguimento do programa nuclear brasileiro, que não é unanimidade entre os setores da sociedade civil organizada, o PSQ é defendido pelas suas "vantagens" econômicas para a região de sua instalação, para a nação e para os setores do capital transnacional envolvidos, bem como é negado pelos movimentos socioambientais e por membros da comunidade local por apresentar a ideia de risco a todo o modo de vida daquelas populações campesinas. $\mathrm{O}$ que se conclui é que se necessita que mais espaços de confronto sejam ampliados a fim de 
democratizar os seus riscos e, em uma tomada de consciência de seus impasses, anteciparmos as ameaças que ele representa para vida do homem e do meio ambiente.

As comunidades de Riacho das Pedras e Morrinhos são casos concretos em que o reconhecimento das ameaças de um projeto que envolve o debate sobre a questão nuclear e o agronegócio se faz com participação, informação e demarcação de posição. Esse confronto não fica restrito aos espaços institucionais, ele valoriza a própria experiência e o território dos moradores impactados, que reconhecem pelo que devem lutar: pela água de seus rios, açudes e cisternas, que são usadas para consumo, lazer e para sua reprodução socioeconômica; e pela qualidade da terra para o cultivo de seus alimentos, para a criação de suas ovelhas, bezerros, galinhas, porcos, etc.

Tanto nas estratégias de convencimento quanto nas de denúncia/oposição, os discursos constituem um saber-poder com seus dispositivos, suas técnicas e táticas (FOUCAULT, 1979), os quais balizam as vantagens, os riscos e perigos na manipulação de produtos e artefatos potencialmente radioativos, disseminando, de alguma forma, na fala do "outro" agricultor, criador ou desempregado, que assimila e significa os elementos constitutivos desse debate a partir de um lugar específico que ocupa nas relações sociais de poder.

Em outras palavras, existe um conflito explícito marcado pela produção e reprodução de verdades sobre riscos, perigos, vantagens e impactos do Projeto Santa Quitéria. E outro conflito implícito que não é pelo estabelecimento de uma "verdade", como haveríamos de cogitar prontamente, mas pelo domínio de um conjunto de orientações (racionais, ambientais, capitalistas) e procedimentos que legitimam as interpretações acerca do Projeto. Como afirma Foucault (1979, p. 13), o combate se dá pelo “[...] conjunto das regras [pode-se falar também dos procedimentos] segundo as quais se distingue o verdadeiro do falso e se atribui ao verdadeiro efeitos específicos de poder. Um combate em torno do estatuto da verdade e do papel econômico-político que ela desempenha"

Não se pretende invalidar o conteúdo "objetivo" perseguido com os procedimentos administrativos seguidos tanto pelos defensores - como a contratação de uma equipe de especialistas para a confecção do EIA-RIMA - quanto pelos opositores - e a confecção também por especialistas de contra relatórios - ou cair em um relativismo infrutífero afirmando ingenuamente que os dados e os argumentos que põem frente a frente os discursos da redenção e ameaça são construídos ficticiamente, no sentido de serem falsos. 


\section{MOBILIZAÇÃO E RESISTÊNCIA AO PROJETO SANTA QUITÉRIA DE MINERAÇÃO DE URÂNIO E FOSFATO: O DESENVOLVIMENTO COMO AMEAÇA E A LUTA ANTINUCLEAR COMO GARANTIA DE EFETIVAÇÃO DA JUSTIÇA SOCIOAMBIENTAL}

Ao contrário, exatamente pelo fato de o PSQ ter um papel econômico, político e cumprir com uma função social segundo interesses e orientações econômicas e políticas ligadas à uma agenda nacional e transnacional de desenvolvimento, os discursos que se confrontam estão lidando constantemente com o que é dito e como dizê-lo; o que é ocultado, ignorado, revelado e para quem se dirige. O que orienta essas questões são decisões políticas que, munidas da linguagem técnico-científica, intentam sua legitimidade.

\section{REFERENCIAS}

BRASIL. Constituição da República Federativa do Brasil. Brasília-DF: Senado Federal, 1988.

Ministério de Minas e Energia. Plano Nacional de Energia 2030 (PNE - 2030).

Brasília: MME: EPE, 2007. (v. 7: Geração Termonuclear) Disponível em:

<http://www.epe.gov.br/PNE/20080512_7.pdf>. Acesso em: 26 jun. 2014.

Ministério de Minas e Energia. Plano Nacional de Mineração 2030 (PNM - 2030).

Brasília: MME, 2010. Disponível em: <http://www.mme.gov.br/sgm/galerias/

arquivos/plano_duo_decenal/Plano_Nacional_de_Mineraxo2030ConsultaPublica10NOV.pdf

>. Acesso em: 03 out. 2014.

BAINES, Stephen G. Terras indígenas e projetos de mineração e usinas hidrelétricas na Amazônia: alternativas de desenvolvimento ou novas formas de dominação. In: Encontro

Anual da Anpocs, 38., 2014, Caxambu. Disponível em: < http://www.anpoc s.org/portal/index.php?option=com_docman\&task=doc_view\&gid=9124\&Itemid=456>. Acesso em: 22 abr. 2015.

BRONZ, Deborah. Empreendimentos e empreendedores: formas de gestão, classificações e conflitos a partir do licenciamento ambiental, Brasil, século XXI. 2011. 504f. Tese

(Doutorado em Antropologia Social) - Programa de Pós-Graduação em Antropologia Social, Museu Nacional, da Universidade Federal do Rio de Janeiro, Rio de Janeiro, 2011.

CALS, Cesar. Um modelo de desenvolvimento para o Ceará. Governo do Estado do Ceará/Secretaria para Assuntos da Casa Civil, 1974.

CONSELHO NACIONAL DO MEIO AMBIENTE - CONAMA. RESOLUÇÃO CONAMA $n^{\circ} 1$, de 23 de janeiro de 1986. Dispõe sobre critérios básicos e diretrizes gerais para a avaliação de impacto ambiental. Publicada no DOU, de 17 de fevereiro de 1986, Seção 1, p. 2548-2549. Disponível em: <http://www.mma.gov.br/port/conama/legiabre.cfm?codlegi=23> Acesso em: 09 abr. 2018. 
CONSELHO NACIONAL DO MEIO AMBIENTE - CONAMA. RESOLUÇÃO CONAMA $n^{\circ} 237$, de 19 de dezembro de 1997. Dispõe sobre a revisão e complementação dos procedimentos e critérios utilizados para o licenciamento ambiental Publicada no DOU, $\mathrm{n}^{\mathrm{o}}$ 247, de 22 de dezembro de 1997, Seção 1, p. 30841-30843. Disponível em:

<http://www.mma.gov.br/port/conama/legiabre.cfm?codlegi=237> Acesso em: 09 abr. 2018.

CONSÓRCIO SANTA QUITÉRIA. RIMA - Relatório de impacto ambiental Projeto Santa Quitéria - CE, Fevereiro, 2014. Disponível em: <http://www.co nsorciosantaquiteria.com.br/arquivos/RIMA.pdf>. Acesso em: 15 maio 2017.

DIAS, Victor Pina; FERNANDES, Eduardo. Fertilizantes: uma visão global sintética. In: BNDES Setorial. Rio de Janeiro, n. 94, p. 97-138, set, 2006. Disponível em: <http://www.bndes.gov.br/SiteBNDES/export/sites/default/bndes_pt/Galerias/Arquivos/conhe cimento/bnset/set2404.pdf>. Acesso em: 20 ago. 2015.

HAESBAERT, Rogério. O mito da desterritorialização: do "fim dos territórios" à multiterritorialidade. 6. ed. Rio de Janeiro: Bertrand Brasil, 2011.

MEDEIROS, Maria Auxiliadora de; DINIZ, Aldiva Sales. A mina de Itataia em Santa Quitéria - CE: o urânio e os riscos da exploração. Revista Casa da Geografia de Sobral, v. 17, n. 1, p. 80-96, março, 2015. Disponível em: 〈http://uvanet.br/rcgs〉. Acesso em: $11 \mathrm{fev}$. 2016.

RIBEIRO, Gustavo Lins. Proyectos de gran escala: hacia un marco conpetual para el análises de una forma de producción temporária. In: BARTOLOMÉ, Leopoldo J. (Org.).

Relocalizados: Antropología Social de las Poblaciones Desplazadas. Buenos Aires: Edicones del ides, 1985. p. 25-47. Disponível em: <http://ides.org.ar/wp-content/uplo ads/2012/05/3_Bartolome.pdf $>$. Acesso em: 24 mar. 2015.

O capital da esperança: a experiência dos trabalhadores na construção de Brasília. Brasília: Editora da Universidade de Brasília, 2008a.

Poder, redes e ideologia no campo do desenvolvimento. Novos Estudos, n. 80, p. 109-125, março, 2008b. Disponível em: <http://www.scielo.br/scie lo.php?pid=S010133002008000100008\&script=sci_arttext $>$. Acesso em: 25 mar. 2015.

ROSA, Luiz Pinguelli et al. Características da estrutura de produção da energia nuclear no Brasil. In: ROSA, Luiz Pinguelli; SIGAUD, Lygia; MIELNIK, Otávio. (Org.). Impactos de grandes projetos hidrelétricos e nucleares: aspectos econômicos e tecnológicos, sociais e ambientais. São Paulo: Editora Marco Zero, 1988.

SANTOS, Potyguara Alencar dos. Reelaboração étnica e novas redes de desenvolvimento no Nordeste brasileiro: a etnogênese Anacé e os projetos de grande escala da Costa do Pecém (CE). 2013. 199f. Dissertação (Mestrado em Antropologia Social) - Programa de PósGraduação em Antropologia Social do Departamento de Antropologia da Universidade de Brasília, Brasília, DF, 2013b. Disponível em:

<http://dan.unb.br/images/doc/Dissertacao_296.pdf>. Acesso em: 24 mar. 2015. 
SASSEN, Saskia. Sociologia da globalização. Tradução de Ronaldo Cataldo Costa. Porto Alegre: Artmed, 2010.

SOUZA, Jessé. A tolice da inteligência brasileira. São Paulo: LeYa, 2015.

VIANNA, Catarina Morawska. A Trilha de Papéis da Usina Hidrelétrica de Belo Monte: tecnologia de cálculo e a obliteração da perspectiva dos povos impactados. In: Revista Anthropológicas, ano 18, 25(2): p. 22 - 40, 2014. Disponível em:

<http://www.revista.ufpe.br/revistaanthropologicas/index.php/revista/article/view/384> Acesso em 09 abr. 2018.

VIDAL, J. W. Bautista. De estado servil à nação soberana: civilização solidária nos trópicos. 2. ed. Petrópolis: Vozes/ Editora Universidade de Brasília, 1988. 